INTERNATIONAL DESIGN CONFERENCE - DESIGN 2018

https://doi.org/10.21278/idc.2018.0126

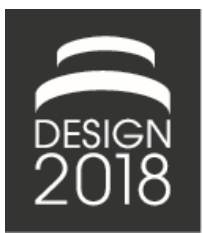

\title{
DESIGN FOR COMPOSITES: TAILOR-MADE, BIO- INSPIRED TOPOLOGY OPTIMIZATION FOR FIBER-REINFORCED PLASTICS
}

\author{
H. Voelkl and S. Wartzack
}

\begin{abstract}
A bio-inspired topology optimization approach with simultaneous fiber orientation optimization for fiber-reinforced plastics is introduced. To scrutinize the optimization potential of the new approach when compared to methods not considering fiber orientation during the optimization process, a case study using a bike rocker arm is presented. In this study, slightly better stiffness behavior of the new approach compared to its counterparts could be observed. However, as far as strength behavior (matrix failure) is concerned, significant gains could be achieved, both in numbers and visually.
\end{abstract}

Keywords: lightweight design, biologically inspired design, topology optimisation, fiberreinforced plastics, design tools

\section{Bio-inspired simultaneous topology and fiber orientation optimization}

Bio-inspired engineering solutions are frequently considered novel and innovative, gaining more and more acceptance in design (Helms et al., 2009; Farel and Yannou, 2013), e.g. for lightweight and ecodesign purposes (Nachtigall, 2002). As described by Helms et al. (2009) there are two processual approaches to bio-inspired design: the problem-driven biologically inspired design process (also referenced as Top-Down approach), which seeks to solve a human need or design problem (Aziz and El sherif, 2016) and the solution-driven process (Bottom-Up), which translates a characteristic biological phenomenon into man-made designs. Helms et al. (2009) states that the solution-driven approach emerged in practice during his study on biologically inspired design.

Likewise, the Soft Kill Option method (SKO) (Baumgartner et al., 1992; Mattheck, 1997) seems to have emerged in practice. It intends to translate adaptive growth, as it is observed with trees or bones, into a structural optimization process using heuristic rules. Highly stressed areas of a design region are stiffened (tree and bone principle) and underloaded areas weakened (bone principle) iteratively, leading to constant stress states throughout the resulting geometry and, thus, a strength-optimized fully-stressed lightweight design. Yet this method does not take anisotropic material properties into account (Mattheck, 1997) - in other words: it simulates a tree without wood fibers.

Thus, a second bio-inspired method was proposed by the group: Computer Aided Internal Optimization (CAIO), translating fiber growth from trees into technical application. It aligns fiber directions with principal stress trajectories and thus reduces "harmful" shear stresses. Figure 1 shows typical results of the two methods. The demonstrator is similarly chosen to DIN ISO 18459:2016-08, in which the aforementioned methods have been standardized (Deutsches Institut für Normung e.V., 2016). 
a) Topology optimization (SKO)

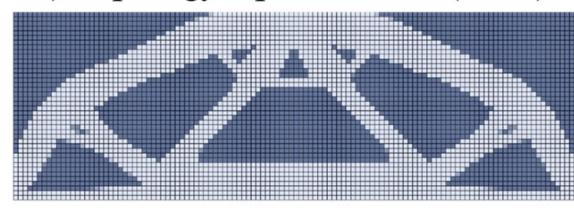

b) Fiber orientation (CAIO)

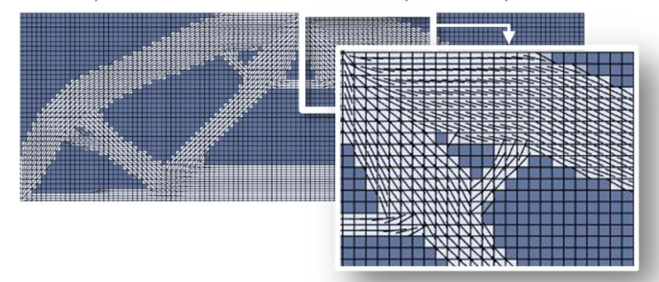

Figure 1. Typical results of Soft Kill Option (a) and CAIO (b)

As these two methods are separated from each other, a sequential approach has to be followed when an optimized design is to be obtained: first, the SKO with isotropic material properties is conducted. Its result is a design proposition (Vajna et al., 2009), the lay-out of the structure within its design region with some areas (finite elements) partly or fully solid and some void - i.e., a topology optimization result (Bendsøe and Sigmund, 2004; Harzheim, 2008). Second, this design proposition is used as input for the CAIO method with an anisotropic material model, which in turn leads to heuristically optimal fiber orientations. This process was expanded and evaluated by Klein et al. (Klein et al., 2013; Klein et al., 2015; Klein, 2017) to derive manufacturable laminate layouts and stackups demonstrating its lightweight design potential. Yet this separation between SKO and CAIO bears an inconsistency: the independent optimization of geometry and fiber layout. Following the stiffness studies in (Nomura et al., 2015b), it can be expected that a simultaneous orientation and topology optimization should lead to stiffer results than its sequential pendant as it is proposed above - or to stay in bio-inspired terms, the tree's fibers shouldn't grow after the branches, but with the branches. Therefore a new bionic topology optimization approach for transversely isotropic materials was developed. Its concept is summed up shortly in the next chapter.

\subsection{Basic methods: SKO and CAIO}

\subsubsection{CAIO (Computer Aided Internal Optimization): Methodology}

Imitating the fiber orientation of trees, the CAIO method is based on the assumption that fibers follow the "load path", i.e. principal normal stress trajectories (Mattheck, 1997). Therefore, a finite element analysis (FEA) is conducted using unidirectional fiber orientations. After that, a stress tensor for each element is extracted and the principal normal stress trajectories are calculated. The orthotropic axis of the material model is aligned with these directions for each element. Another FE analysis is conducted, which, due to the varied fiber orientations, leads to a new stress distribution. Using this new distribution, the next iteration is carried out. This process is repeated until convergence is reached. The convergence indicator is the reduction of shear stresses within the part to be optimized. (Mattheck and Tesari, 2000) A flow diagram of the optimization algorithm is shown in Figure 2.

\section{CAIO method}

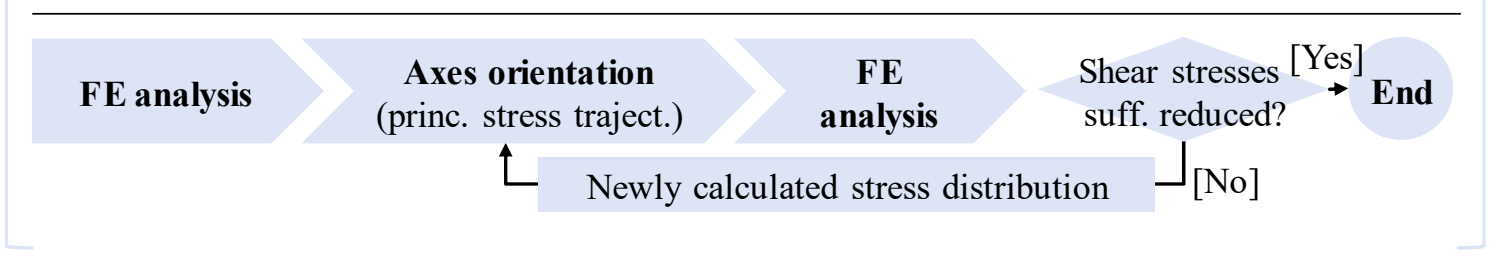

Figure 2. CAIO method as proposed in (Mattheck and Tesari, 2000)

The algorithm shows fast convergence, as examined by Klein (2017) and the author. It can be expected to deliver very good, or even optimal, stiffness results: Aligning fiber orientation with maximum principal normal stress directories (i.e., those with maximum absolute eigenvalue (Spickenheuer, 2014)) of a structure under some assumptions (e.g. one loadcase, shear-weak material) delivers globally optimal 
compliance results as shown by (Cheng and Pedersen, 1997) and (Luo and Gea, 1998). Moreover, tests with tensile samples implied favorable strength properties of the CAIO-optimized specimens as shown in (Reuschel and Mattheck, 1999).

\subsubsection{SKO (Soft Kill Option): Methodology}

Translating bone growth into an engineering solution, the SKO method as proposed by (Baumgartner et al., 1992) is considered a heuristic topology optimization algorithm (Harzheim, 2008) with some similarities to optimality criterion methods (Rozvany, 2009). Figure 3 illustrates the SKO method.

\section{SKO method}

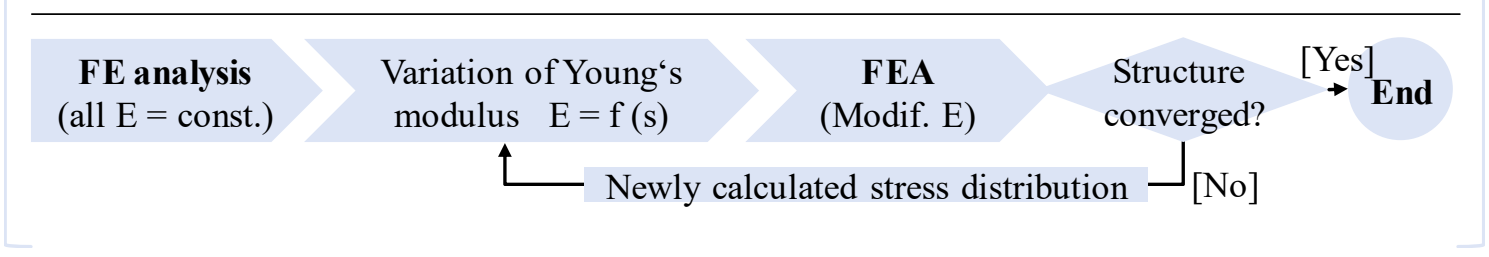

Figure 3. SKO method as proposed in (Mattheck and Tesari, 2000)

At first, a FEA is conducted with all elements being equally stiff (i.e. the Young's modulus of each element is constant). Following the von Mises stress of each element, the respected Young's modulus is adapted according to Equation 1. Frequently, the variation of the modulus is achieved using temperatures at nodes as an intermediate controlling stage, which is skipped here.

$$
E_{i, t}=E_{i, t-1}+s\left(\sigma_{i, t-1}-\sigma_{r e f}\right)
$$

In the current iteration $t$, the Young's modulus $E$ of element $i$ is calculated by the previous iteration's Young's modulus plus a scaling factor $s$ multiplied with a stress term. The scaling factor emulates the bone mineralization growth speed - the larger it is chosen, the greater the changes according to the stress state. The stress state is reflected in a stress term, which uses a given reference von Mises stress value $\sigma_{r e f}$. If the previous iteration's element equivalent stress value $\sigma_{i, t-1}$ is larger than the reference value, the term becomes positive and vice versa. If it is vastly larger, the term also becomes much larger (or vice versa, strongly negative). In combination with the scaling factor it increases the previous Young's modulus when the element is "over-stressed" and decreases it if "under-stressed". Obviously, the reference stress is arbitrary or set to certain strength targets. In terms of topology optimization, it controls the volume fraction to be left over from the whole design region. If the reference stress is chosen very low, many elements are considered highly stressed, provoking a stiffer structure by more material overall and vice versa.

The algorithm, like CAIO, also shows fast convergence (Mattheck and Tesari, 2000). Its heuristic nature makes it easily understandable. Also, as pointed out in (Harzheim, 2008), for isotropic and incompressible material, assuming only one load case, the SKO method delivers a maximum stiffness design by leading to constant strain energy density on the structural surface. Yet, it lacks some basic topology optimization capabilities: 1. Pre-defining a volume fraction is not possible, as this output depends on $\sigma_{\text {ref }}$; 2. It is lacking a minimum member size filter to achieve both mesh independent (Sigmund and Petersson, 1998) and more manufacturable designs; 3. Convergence control is complicated due to the mutually dependent scaling factor $\mathrm{s}$ and overall stress state (if overall stress is very low, the scaling factor has to be huge to provoke significant structural change).

Emerging from advantages and disadvantages of both methods, a combination of CAIO and SKO is developed to make a comprehensive optimization possible, using anisotropic material models, including minimum member size control and enabling fast convergence with a volume fraction restriction.

\subsection{Combination of CAIO and SKO: Methodology, capabilities}

The concept of the combined approach named $m f k$ TOPO was initially presented in (Völkl et al., 2017). Its main working principle is illustrated in Figure 4. 


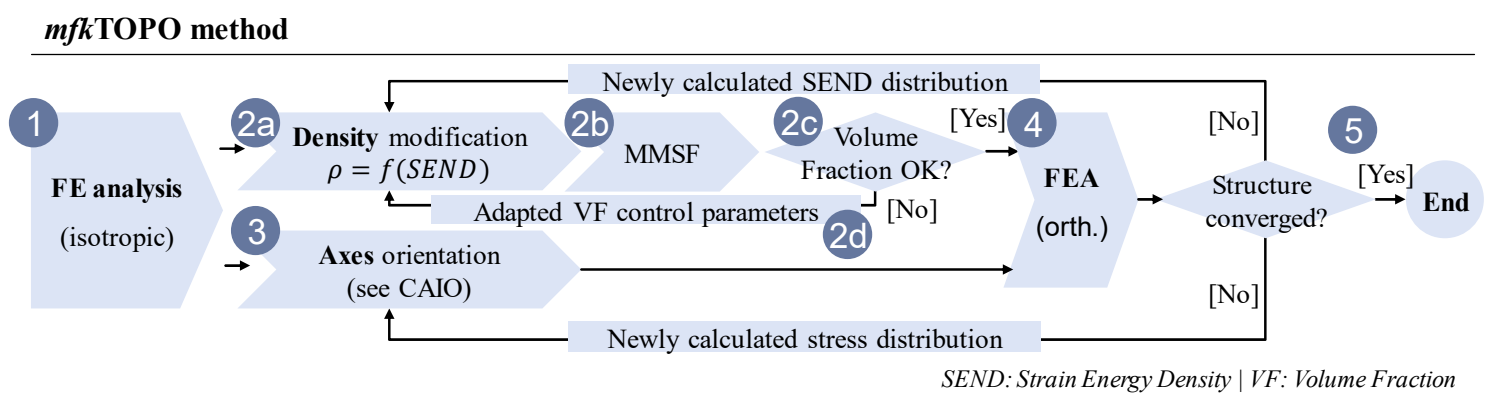

Figure 4. Process chart of the new combined approach

First, a FE model containing all loads and boundary conditions is set up and solved using an isotropic material model, step (1) in Figure 4. From its element results two inputs for the optimizer are derived:

1. Strain Energy Density, as an input to stiffness control, translates into material distribution (realized by so-called densities (Bendsøe and Sigmund, 2004)).

2. Principal Stress Trajectories, sometimes referred to as force flow (Mattheck and Tesari, 2000), translate into fiber axes orientations.

Thus the two essential questions of topology optimization with simultaneous fiber orientation are answered: 1 . Where material is needed and where can be done without and 2 . Under which angle the fibers should be placed. To enable more concise understanding of the whole workflow, Figure 5 illustrates the sub process (2a)-(2c) and (3), i.e. material distribution and fiber orientation.

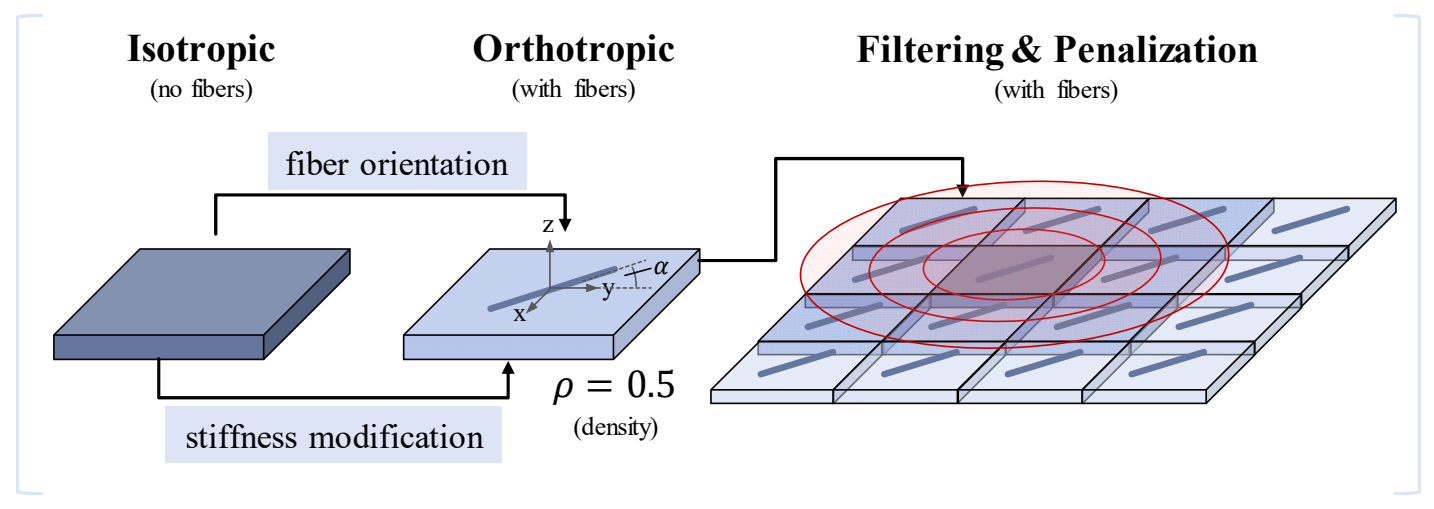

Figure 5. Sub process of material distribution and fiber orientation

The minimum member size filter, which is illustrated on the right side of Figure 5 and step (2b) in Figure 4, serves two purposes: 1. Ensure mesh independency (i.e., finer meshes don't automatically lead to finer structures) and 2. Guarantee a minimum structural member size to keep the result as manufacturable as possible. The minimum member size filter is implemented similar to (Sigmund and Petersson, 1998). Furthermore, the illustration shows "grey" areas, which means the material is not distributed in a full-hole (0/1-density) way, which makes the derivation of design proposals difficult. Usually, for a design proposition a clear 0/1 proposition is desired (Bendsøe and Sigmund, 2004) instead of various grey areas. This is achieved by a so-called penalty factor. The densities are raised to the power of a penalty parameter $p$ - usually gradually during iterations from 0 to about 2-4 (Rozvany, 2009) - thus for example a "grey element value" of 0.3 becomes $0.3^{3}=0.027$ and the element is cancelled out (representing a "hole"). From the material distribution steps - new densities per element and filtering/penalization - a volume fraction emerges depending on a, initially arbitrary, threshold (2c). If this volume fraction is not as desired, e.g. to achieve a weight reduction target, the process is now iteratively repeated while adjusting the threshold $(2 \mathrm{~d})$ until the target volume fraction is reached.

Using the new fiber orientations and densities, a FEA with anisotropic material properties is conducted (4). The process is repeated iteratively until the structure has converged or a maximum number of 
iterations is reached (5). This method thus combines the advantages of heuristic optimizers like fast convergence speed, comprehensibility and foundation in engineering practice with some flexibilities of mathematical optimizers, such as minimum member size filtering and fixed volume fraction to achieve high-stiffness, high-strength designs.

Depending on the material model, different structures result from the algorithm. For example, for an isotropic steel material model, the result is close to identical to classical topology optimizer results (see for example Figure 6a). Yet, when using anisotropic materials, the behavior changes. As the new optimization approach is originally intended for Carbon Fiber Reinforced Plastic (CFRP), which is transversely isotropic (Schürmann, 2007), just material models exhibiting this special case of anisotropy will be examined in this paper.

To give an intuitional idea of what should happen, a fictitious material can be imagined which can only bear loads parallel to the fiber (matrix modulus and fiber lateral modulus are both zero). The resulting optimal structure should only contain one-dimensional compression and tension rods, while the optimal structure for a steel model can and should contain two-dimensional structural elements, of course (three-dimensional structures are not of interest here, as - arbitrarily shaped - shell geometries are desired for laminates). Figure 6 illustrates this idea using optimizations conducted with the material properties of steel (6a) and the tension/compression-only material (6b), also depicting the in-plane shear stresses.

a) Isotropic material model

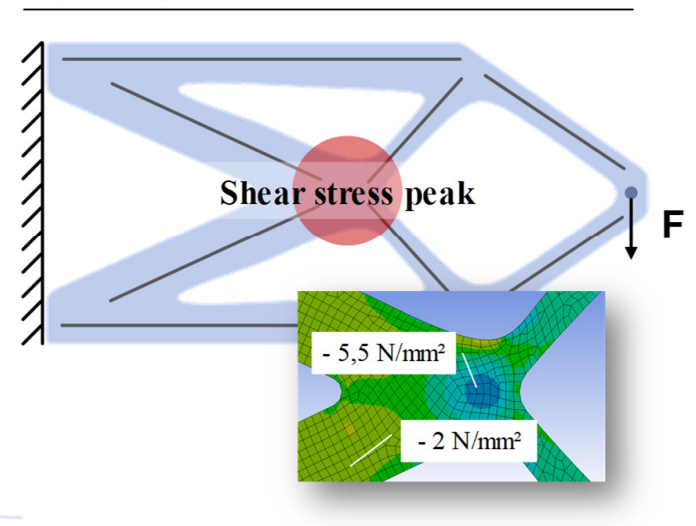

b) Anisotropic (tension/compression only)

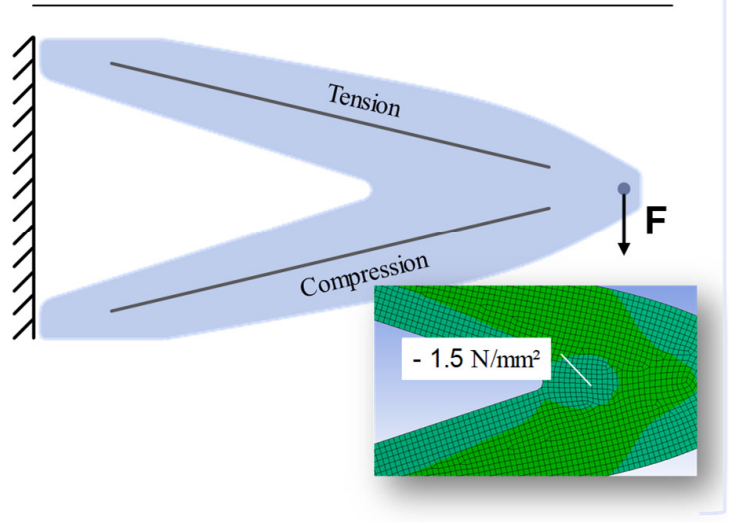

Figure 6. Short cantilever - isotropic vs. tension/comp ression-only-material model

Classical topology algorithm results for the problem above (Figure 6a) lead to structures similar to (Michell, 1904) with orthogonal joints, which in turn leads to multi-axial stress states in these regions, e.g. the shear stress peak in the middle of the optimization result with isotropic material model on the left. For the tension/compression-only material structures similar to tension- and compression rods without any joints are expected to evolve (6b) as the material simply cannot bear lateral stresses.

In the following chapter, the bionic topology optimization approach is applied to a bike rocker arm design problem. Its usefulness is scrutinized by comparing optimization results based on an isotropic material model (steel) to results of the new approach considering transversal isotropy, first regarding stiffness, then strength.

\section{Tailoring topology optimization for FRP: Case study}

\subsection{Application example: Bike rocker arm}

Rocker arms are used in many applications, such as mounting a spring within a bicycle frame. The example was chosen as it is close to the existing industrial application of CFRP within bicycle manufacturing and various other sports equipment (Schürmann, 2007). Figure 7 introduces the demonstator. A similar design problem has also been used for teaching about mistakes made in topology optimization in (Mudigonda, 2016). 


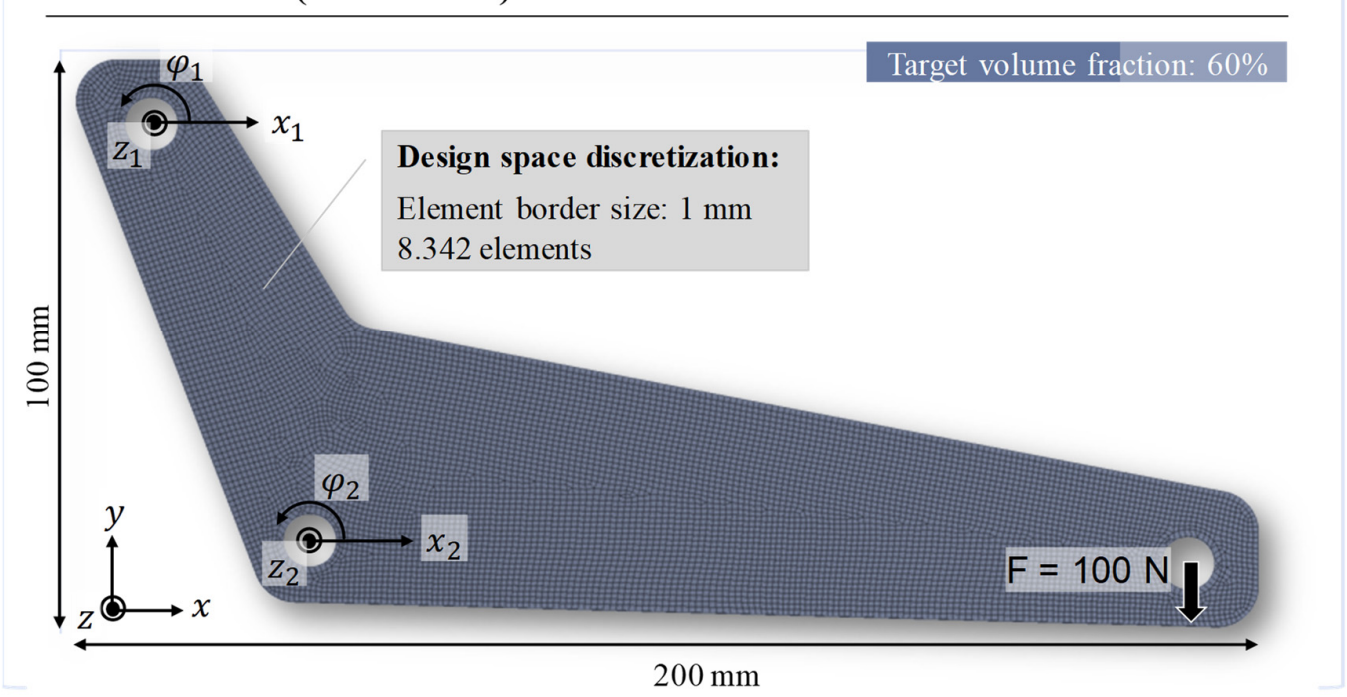

Figure 7. Demonstrator: Bike rocker arm

The rocker arm with three drill-holes is meshed with 8,342 second-order shell (triangular and rectangular) elements with a side length of about $1 \mathrm{~mm}$ each. Rotational degrees of freedom at the borders of the two drill-holes on the left $\varphi_{1}$ and $\varphi_{2}$ are left free, while movement in other directions is suppressed to roughly simulate the use of the rocker within a bike frame. A force of $100 \mathrm{~N}$ is applied to the drill-hole on the right as shown. As far as typical topology optimization parameters are concerned, a volume fraction (to be kept after optimization) of $60 \%$ was specified. This could typically emerge from weight targets. A minimum member size radius of $6 \mathrm{~mm}$ was specified, describing half of the minimum structural member diameter. Thus, manufacturability can be improved. More specific parameters contain the penalty factor, which is raised from 1 in the first iteration in steps of 0.05 to its maximum of 3; one single layer is optimized (2D problem in terms of both geometry and stress). The objective function, set for the benchmark mathematical optimizers, is minimum compliance (maximum stiffness).

Two material models were used for comparison: a CFRP model based on the ANSYS material database versus a steel model. Respective parameters are given in Table 1.

Table 1. Material model settings

\begin{tabular}{|l|l|l|l|l|l|l|}
\hline Parameter & E1 & E2 & GXY & GXZ & PRXY & PRXZ \\
\hline Unit & \multicolumn{9}{|c|}{$\mathrm{N} / \mathrm{mm}^{2}$} & &. \\
\hline CFRP & 123.340 & 7.780 & 5.000 & 3.080 & 0.27 & 0.42 \\
\hline Steel & 210.000 & 210.000 & 76.000 & 76.000 & 0.3 & 0.3 \\
\hline
\end{tabular}

\subsection{Topology optimization results}

\subsubsection{Benchmark methodology and resulting geometries}

Three different topology optimization routines are compared:

1. $m f k$ TOPO (the new approach): using the steel material model

2. ANSYS 18.1 topology optimization: also using the steel material model

3. $m f k$ TOPO: using the CFRP model

First, the optimization problem is solved using the new approach with fiber orientations "switched off", using the steel material model. To ensure plausibility with other topology optimizers, this result is compared to ANSYS topology optimization from ANSYS 18.1. After these two optimizations, the final "tailored" optimization is carried out with $m f k$ TOPO using the CFRP material model introduced above. The resulting geometries with $60 \%$ volume fraction are shown in Figure 8. 


\section{Optimization Results}

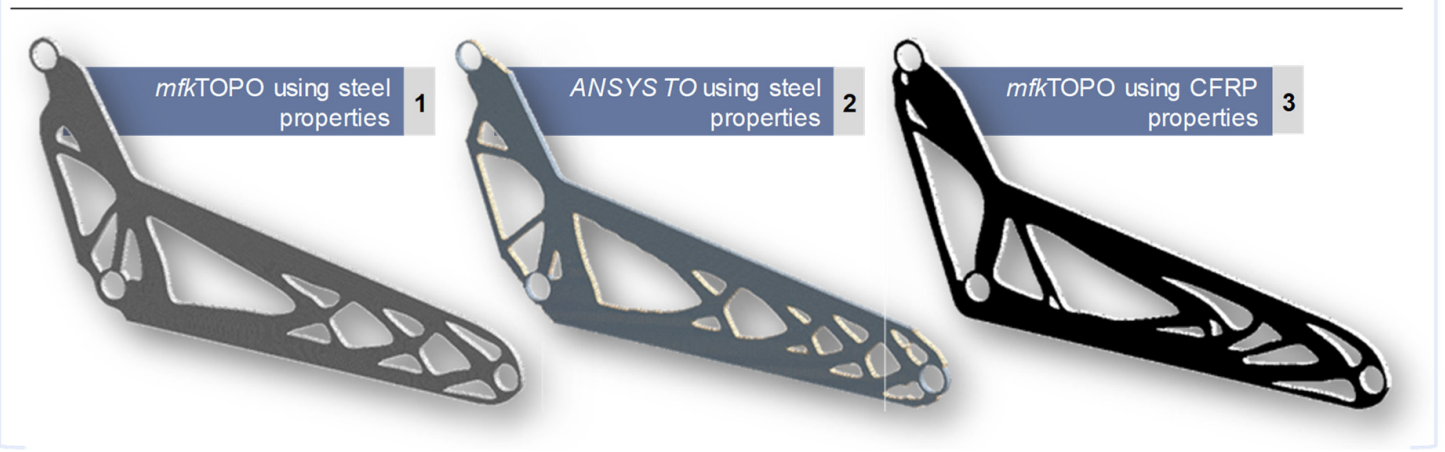

Figure 8. Topology optimization results

Results of the first two optimizations (mfkTOPO isotropic/ANSYS topology optimization) are very similar, even though their working principle is completely different - mfkTOPO uses a heuristic optimization principle, while ANSYS topology optimization uses sequential convex programming (ANSYS, 2017) - and the element types are also different due to individual capabilities of the two optimization routines. The left section close to the boundary holes from $m f k T O P O$ (1) is close to identical to the left section from ANSYS (2). The right section close to the hole where the load is applied differs between the two, with finer structures in the ANSYS result (2). Thus there's some difference to be expected within stiffness and strength results, which are examined further below.

The CFRP result on the right is obviously much different, exhibiting less orthogonal joint locations. Also the left section close to the boundaries consists of straightforward compression/tension trusses with much less joints than for the steel model optimizations - which fits the expectations from chapter 1 , considering the comparatively unfavorable matrix stiffness properties of CFRP.

\subsubsection{Stiffness comparison}

Now, in a first step, a steel material model is applied to all three designs. Hypothetically, this should lead to better stiffness results for design 1 and 2 than for design 3, as design 1 and 2 are optimized specifically for this material. The slightly differing volume fraction of the three designs (maximum difference about 1.3 percentage points) emerges from the topology reconstruction from raw result into CAD. Yet, more material misleadingly causes stiffer designs, distorting the results. Thus, it is considered similarly to the "efficiency adaption" presented in (Rozvany, 2009) by multiplying strain energy and volume fraction for what is called "adapted strain energy" here. Figure 9 shows the results.

Stiffness comparison: Steel material model

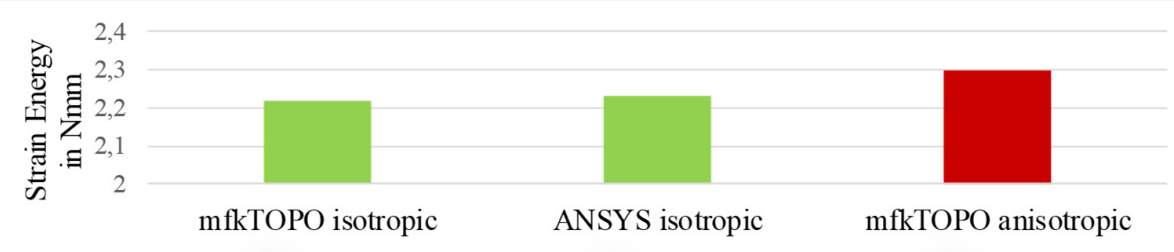

\begin{tabular}{|l|l|l|l|}
\hline $\begin{array}{l}\text { Strain Energy in Nmm } \\
\begin{array}{l}\text { Volume Fraction after } \\
\text { Reconstruction }\end{array}\end{array}$ & 3.67 & $6.4 \%$ & 3.69 \\
\hline $\begin{array}{l}\text { Adapted Strain } \\
\text { Energy }\end{array}$ & 2.22 & 2.23 & $2.30(+3.2 \%)$ \\
\hline
\end{tabular}

Figure 9. Stiffness comparison - steel material model for different geometries 
As stiffness maximization means compliance minimization (Bendsøe and Sigmund, 2004), a better result is indicated by a smaller total strain energy (half of compliance). All designs are simulated using steel as their material model. As expected, the result optimized for a transversely isotropic material model performs worse (about $3 \%$ less stiff) than the geometries specifically tailored for steel due to the use of this material during optimization.

However, as described above, commonly available topology optimization tools (and many research tools, too) are not capable of taking transversal isotropy into account. The less optimal results of this lack of "tailoring" is shown in Figure 8, when using CFRP for all geometries. To achieve comparable and optimal results for this one-loadcase design, the fiber direction (principal axis of orthotropy) within each finite element is aligned with maximum (absolute-eigenvalue (Spickenheuer, 2014; Klein, 2017)) principal normal stress trajectories. Further theoretical background to this and prerequisites under which this optimality condition holds true (fulfilled by the CFRP model used here) are given in (Cheng and Pedersen, 1997; Luo and Gea, 1998). Figure 10 summarizes the stiffness results.

Stiffness comparison: CFRP material model

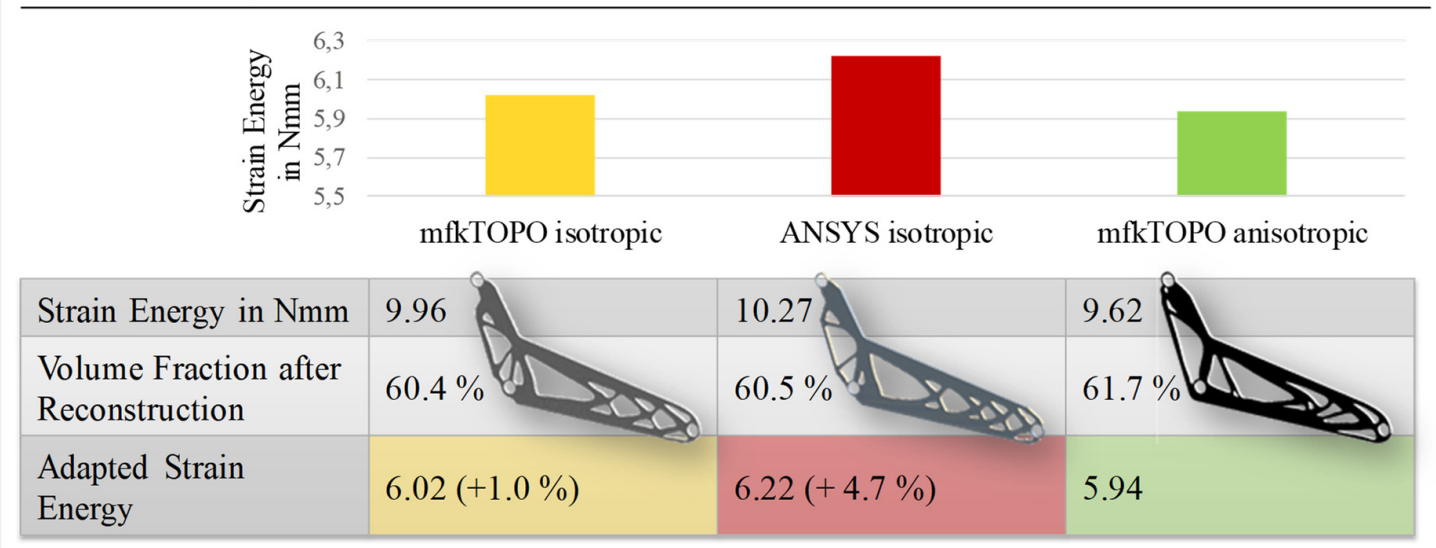

Figure 10. Stiffness comparison - CFRP material model for different geometries

Overall, the mfkTOPO result using the transversely isotropic CFRP material model for optimization shows the most favorable results, as expected, being 1 to $4.7 \%$ stiffer than its counterparts. Similar stiffness gains were noted for one-loadcase examples by (Nomura et al., 2015a). However, higher stiffness gains are expected when considering multiple load cases, which is intended to be scrutinized in future publications.

The original SKO method, which lays one of the foundations for the new topology optimization approach, creates strength-optimized designs (Harzheim, 2008) as it refers to an equivalent stress threshold. Additionally, the increase in stiffness and less orthogonal joint locations allow the assumption that matrix failure is less likely due to better usage of the fibers. Thus also strength evaluation will be conducted with two of the design propositions above in the following subchapter. The $m f k$ TOPO steel result was chosen due to the very similar result when compared to ANSYS topology optimization.

\subsubsection{Strength comparison}

Strength comparison is conducted using the Puck matrix criterion (Knops, 2008), which indicates to what degree the matrix is stressed (the higher, the more critical) and whether failure in the matrix occurs (value $\geq 1$ ) or not (value $<1$ ). Failure in the matrix is frequently caused by lateral tension; moreover, it can also be caused by lateral compression and various shear stress states (Schürmann, 2007). Expressed the other way round, in general, uniaxial stress states are favorable for transversely isotropic materials (Michaeli et al., 1995). Figure 11 shows the resulting Puck matrix criterion distribution, red color indicating increasingly critical, blue uncritical strength values. 
Strength comparison (PUCK matrix failure criterion)

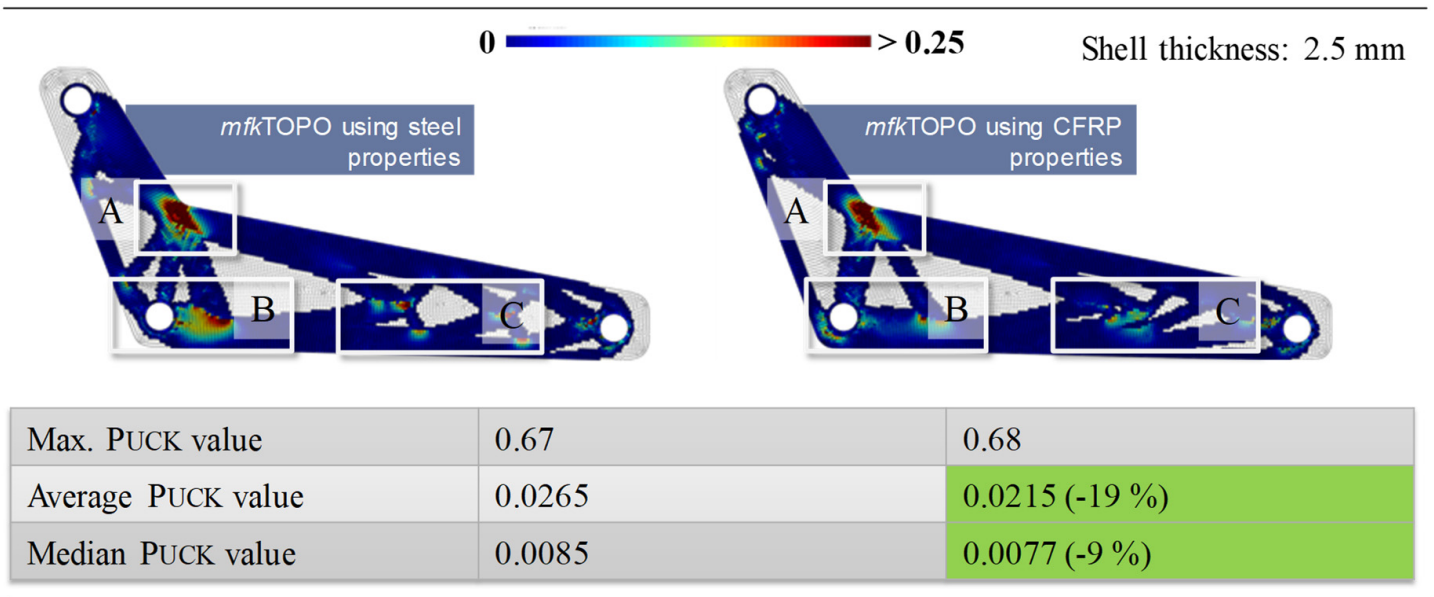

Figure 11. Strength comparison

The optimization result, optimized for steel (left) exhibits higher and more widely distributed Puck matrix failure values (e.g. detail B and joint locations in detail C, see also Figure 10 below). Maximum Puck value is about the same for both designs at the notch point $\mathrm{A}$, which was intentionally designed this way - but could also result from real design space restrictions. Both average and median Puck matrix failure criterion values are much better (-19\% for average, $-9 \%$ for median) when considering CFRP material properties already during the optimization. Figure 12 shows a zoom on detail A, B, and $\mathrm{C}$.

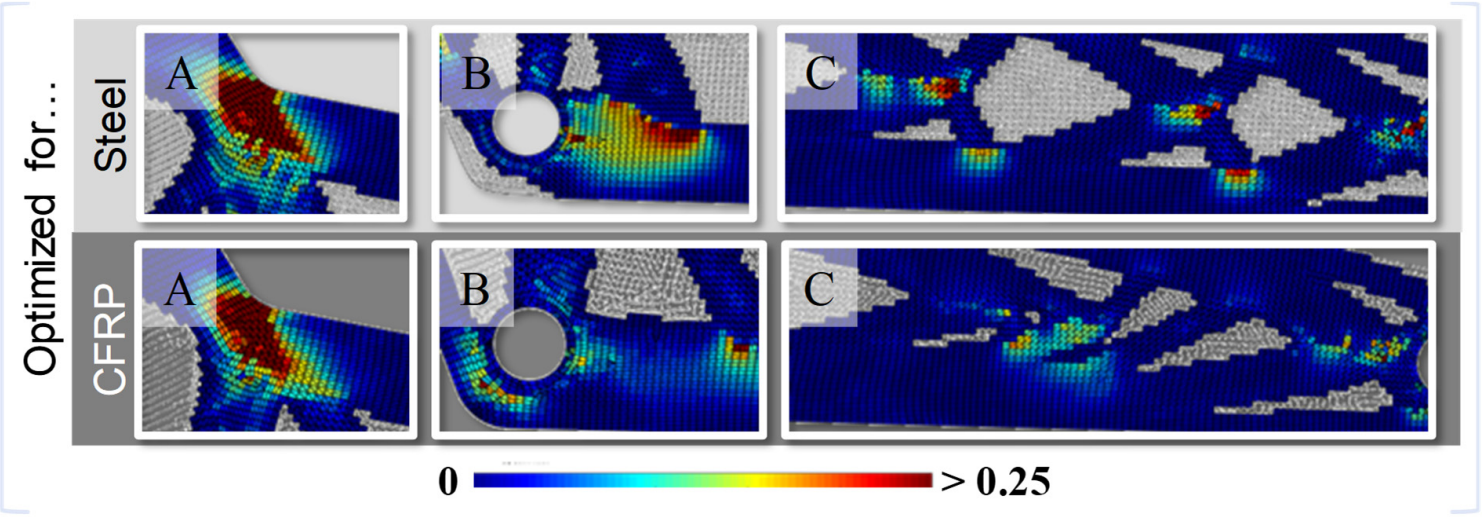

Figure 12. Detail view of critical regions

Detail A represents the region of highest stresses. The design optimized for steel shows a bit more widely distributed failure values, yet overall stress is high in both cases, leading to high Puck values already due to stress intensity in general - i.e. not necessarily due to an inappropriate loading of fibers and matrix. In detail B and C, it becomes clear that specific optimization for CFRP is worth the effort: due to less orthogonal joints the matrix is much less loaded (or, the other way round, fibers seem to be loaded more adequately). To conclude the analysis quantitatively, the greater appearance of critical values overall can also be seen from the histogram in Figure 13.

Optimization for the "wrong" material obviously leads to more frequent appearance of higher Puck matrix values in the steel-optimized case. As many regions are rather uncritical for matrix failure due to uniaxial stress states (more or less all blue regions in Figure 9), this also is reflected in the histogramm on the vertical axis between 0 and 0.1 . 


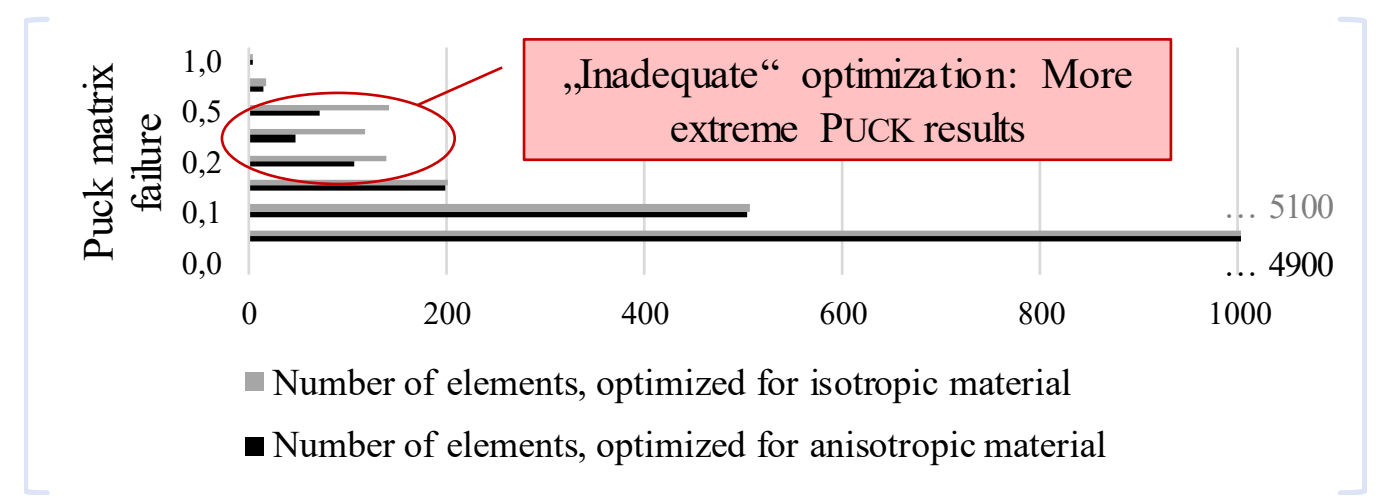

Figure 13. Increase of critical matrix failure values (failure values scaled to $\max =1$ )

\section{Summary and outlook: Stiffness, strength, manufacturability}

A bio-inspired, empirical topology optimization approach with simultaneous fiber orientation optimization was introduced. Its base methods, SKO and CAIO, were adapted, extended and combined to match typical topology optimization requirements. A case study using a bike rocker arm was conducted in order to scrutinize the optimization potential of the new approach when compared to methods not considering anisotropy during the optimization process.

Better stiffness behavior of the new approach compared to its counterparts could be observed. In accordance with (Nomura et al., 2015a) the stiffness gain was in the range of single-digit percentage points. However, as far as strength behavior (matrix failure) is concerned, significant gains could be observed, both in numbers and visually. Thus, a promising geometry proposal is given, which can serve as a starting point for the subsequent design of advanced multi-layer composite structures.

Concerning practical applications, the following propositions are made:

- The geometry proposition, reconstructed in $\mathrm{CAD}$, could be used for laminate optimization software as provided by Altair OptiStruct or as an input for the approach as presented by Klein (2017). As the new approach naturally tends to generate areas of uniaxial stresses, it can be expected that the optimized laminate structure (multi-layer, multi-orientation) will be simplified compared to areas of highly multiaxial stress states, which can be provoked by optimizers using steel properties. This might be especially relevant, for example, in areas of high shear stresses as caused by torsion.

- Alternatively, the structure could be printed directly using additive manufacturing - "bridging" the gap between topology optimization results and final products (Zegard and Paulino, 2016). To consider fiber orientations, short fiber-reinforced filament could be used. The print direction could steer the axis of orthotropy.

\section{References}

ANSYS (2017), ANSYS Help, SAS IP, Inc.

Aziz, M.S. and El sherif, A.Y. (2016), "Biomimicry as an approach for bio-inspired structure with the aid of computation", Alexandria Engineering Journal, Vol.55 No. 1, pp. 707-714. https://doi.org/10.1016/j.aej.2015.10.015

Baumgartner, A., Harzheim, L. and Mattheck, C. (1992), "SKO (soft kill option): the biological way to find an optimum structure topology", International Journal of Fatigue, Vol. 14 No. 6, pp. 387-393.

Bendsøe, M.P. and Sigmund, O. (2004), Topology optimization: Theory, methods, and applications, 2nd ed., Springer, Berlin.

Cheng, G. and Pedersen, P. (1997), "On sufficiency conditions for optimal design based on extremum principles of mechanics", Journal of the Mechanics and Physics of Solids, Vol. 45 No. 1, pp. 135-150. https://doi.org/10.1016/S0022-5096(96)00070-1

Deutsches Institut für Normung e.V. (2016), Biomimetics - Biomimetic structural optimization, No. 18459, 2016-08, Beuth Verlag, Berlin. 
Farel, R. and Yannou, B. (2013), Bio-inspired ideation: Lessons from teaching design to engineering students: ICED 13, the 19th International Conference on Engineering Design, 19th - 22nd August 2013, Sungkyunkwan University (SKKU), Seoul, Korea, DS / The Design Society, Vol. 75, Design Society, Castle Cary, Somerset.

Harzheim, L. (2008), Strukturoptimierung: Grundlagen und Anwendungen, 1st ed., Deutsch, Frankfurt am Main.

Helms, M., Vattam, S.S. and Goel, A.K. (2009), "Biologically inspired design. Process and products", Design Studies, Vol. 30 No. 5, pp. 606-622. https://doi.org/10.1016/j.destud.2009.04.003

Klein, D. (2017), "Ein simulationsbasierter Ansatz für die beanspruchungsgerechte Auslegung endlosfaserverstärkter Faserverbundstrukturen", Dissertation, Friedrich-Alexander-Universität ErlangenNürnberg, Erlangen-Nürnberg

Klein, D., Caballero, S. and Wartzack, S. (2013), "Evaluierung unterschiedlicher Theorien zur Berechnung beanspruchungsgerechter Faserorientierungen in CFK-Strukturen", DFX 2013: Proceedings of the 24th Symposium Design for $X$.

Klein, D., Malezki, W. and Wartzack, S. (2015), "Introduction of a computational approach for the design of composite structures at the early embodiment design stage", Proceedings of the 20th International Conference on Engineering Design (ICED 15) Vol 6: Design Methods and Tools-Part 2 Milan, Italy, July 27-30, 2015.

Knops, M. (2008), Analysis of failure in fiber polymer laminates: The theory of Alfred Puck, 1st ed., Springer, Berlin.

Luo, J.H. and Gea, H.C. (1998), "Optimal orientation of orthotropic materials using an energy based method", Structural Optimization, Vol. 15 No. 3-4, pp. 230-236.

Mattheck, C. (1997), "Design in der Natur und nach der Natur”, Wirtschaftsingenieur, Vol. 40, pp. 10-14.

Mattheck, C. and Tesari, I. (2000), "Design in nature", In: Ibarra-Berastegi, G. and Zanneti, P., Development and application of computer techniques to environmental studies 8, WIT Press; WIT, Southampton UK, Boston.

Michaeli, W., Huybrechts, D. and Wegener, M. (1995), Dimensionieren mit Faserverbundkunststoffen: Einführung und praktische Hilfen, Hanser, München.

Michell, A. (1904), "LVIII. The limits of economy of material in frame-structures", Philosophical Magazine, Vol. 8 No. 47, pp. 589-597. https://doi.org/10.1080/14786440409463229.

Mudigonda, G. (2016), Thought Leader Thursday: Five Common Mistakes made Running Topology Optimization. [online] Available at: http://innovationintelligence.com/thought-leader-thursday-fivecommon-mistakes-made-running-topology-optimization/ (accessed 19.10.2017).

Nachtigall, W. (2002), Bionik: Grundlagen und Beispiele für Ingenieure und Naturwissenschaftler ; mit 440 Abbildungen, 2., Springer, Berlin.

Nomura, T., Dede, E., Tadayoshi, M. and Atushi, K. (2015a), "Simultaneous Optimization of Topology and Orientation of Anisotropic Material using Isoparametric Projection Method", Proceedings of the 11th World Congress on Structural and Multidisciplinary Optimization.

Nomura, T., Dede, E.M., Lee, J., Yamasaki, S., Matsumori, T., et al. (2015b), "General topology optimization method with continuous and discrete orientation design using isoparametric projection", International Journal for Numerical Methods in Engineering, Vol.101 No.8, pp. 571-605. https://doi.org/10.1002/nme.4799.

Reuschel, D. and Mattheck, C. (1999), “Optimization of fiber arrangement with CAIO (computer aided internal optimization) and application to tensile samples", WIT Transactions on the Built Environment, Vol. 40, pp. $247-255$.

Rozvany, G.I.N. (2009), "A critical review of established methods of structural topology optimization", Structural and Multidisciplinary Optimization, Vol. 37 No. 3, pp. 217-237. https://doi.org/10.1007/s00158007-0217-0.

Schürmann, H. (2007), Konstruieren mit Faser-Kunststoff-Verbunden, 2nd ed., Springer, Heidelberg.

Sigmund, O. and Petersson, J. (1998), "Numerical instabilities in topology optimization: A survey on procedures dealing with checkerboards, mesh-dependencies and local minima", Structural Optimization, Vol. 16 No. 1, pp. 68-75.

Spickenheuer, A. (2014), "Zur fertigungsgerechten Auslegung von Faser-Kunststoff-Verbundbauteilen für den extremen Leichtbau auf Basis des variabelaxialen Fadenablageverfahrens Tailored Fiber Placement”, Fakultät Maschinenwesen, Technische Universität Dresden, Dresden.

Vajna, S., Bley, H., Hehenberger, P., Weber, C. and Zeman, K. (2009), CAx für Ingenieure: Eine praxisbezogene Einführung, 2., völlig neu bearb. Aufl., Springer Berlin Heidelberg, Berlin, Heidelberg.

Völk1, H., Franz, M. and Wartzack, S. (2017), "Topologieoptimierung mit transversal isotropem Materialmodell - Produktentwickler auf der Suche nach der optimalen Geometrie für Faser-Kunststoff-Verbunde”, Design 
for X: Beiträge zum 28. DfX-Symposium, Bamberg, 10.04.2017-10.05.2017, TUTECH Verlag, Hamburg, pp. 203-214.

Zegard, T. and Paulino, G.H. (2016), "Bridging topology optimization and additive manufacturing”, Structural and Multidisciplinary Optimization, Vol. 53 No. 1, pp. 175-192. https://doi.org/10.1007/s00158-015-12744.

Harald Voelkl, M. Sc.

Friedrich-Alexander-Universität Erlangen-Nürnberg, Chair for Engineering Design

Martensstrasse 9, 91058 Erlangen, Germany

Email: voelkl@mfk.fau.de 